\title{
The Role of Intraoral and Gastrointestinal Cues in the Control of Sucking and Milk Consumption in Rat Pups
}

\author{
STEPHEN C. BRAKE \\ D. JAYNE SAGER \\ REGINA SULLIVAN \\ MYRON HOFER \\ Department of Psychiatry \\ Montefiore Medical Center \\ and the Albert Einstein College of Medicine \\ Bronx, New York
}

\begin{abstract}
Nutritive deprivation, suckling deprivation, gastronintestinal fill, and milk availability contribute to the control of sucking (as measured by jaw-muscle electromyograph) and ingestion of milk (provided via a tongue cannula) in 11-13-day-old rat pups. Depriving pups of the opportunity to suckle reliably increases subsequent sucking and milk intake. Intraoral delivery of milk also increases sucking, regardless of whether or not pups are suckling-deprived. Gastrointestinal preloads have no effect on sucking if pups are not receiving milk, but reliably block the increase in sucking which accompanies milk delivery. Finally, milk delivered to the pup's mouth prior to a suckling opportunity can either enhance or attenuate subsequent sucking depending on whether pups are allowed to consume milk while suckling. In all cases, a particular mode of sucking ("rhythmic" sucking) is most affected by experimental manipulation, and appears to be an important component of the pup's ingestive behavior.
\end{abstract}

There are at least 2 ways that a suckling infant might control the amount of milk it consumes from the nipple. It might vary the amount of time it spends attached to the nipple or it might vary the frequency and intensity of its suckling while on a nipple. Infant rats do not appear to employ the 1st strategy until they are about 15 days old. Before this age, a pup's latency to attach to a nipple, the time it spends attached to a nipple, and the number of times it will shift from 1 nipple to another are not affected by privational status (Cramer, Blass, \& Hall, 1980; Hall \& Rosenblatt, 1977; but see Dollinger, Holloway, \& Denenberg, 1978). Nevertheless, pups younger than 15 days of age do control the amount of milk they consume according to whether they are maternally deprived or have received gastric preloads (Hall \& Rosenblatt, 1978; Houpt \& Epstein, 1973; Lorenz, Ellis, \& Epstein, 1982), suggesting that it is the 2nd strategy that they employ.

We have shown that pups ranging in age from 3 to 20 days do indeed alter the frequency and patterning of their sucking as a consequence of privational status (Brake

Reprint requests should be sent to Stephen C. Brake, Department of Psychiatry, Montefiore Hospital and Medical Center, 111 East 210th Street, Bronx, New York 10467, U.S.A.

Received for publication 15 June 1981

Revised for publication 13 April 1982

Developmental Psychobiology, 15(6):529-541 (1982)

(C) 1982 by Iohn Wiley \& Sons, Inc. 
\& Hofer, 1980; Brake, Sullivan, Sager, \& Hofer, 1982; Brake, Wolfson, \& Hofer, 1979). At all ages, but particularly during the 1 st 2 weeks, maternal deprivation increases the frequency of a mode of sucking which we call rhythmic sucking, while having little effect on more erratic, arrhythmic sucking. We have also found that pups engage in rhythmic sucking (and limb movement) immediately following milk-ejection (Shair, Brake, \& Hofer, 1982), and that rhy thmic sucking is increased to an even greater extent if milk is continuously available (Brake et al., 1982). This close linkage of rhythmic sucking with the nutritive consequences of suckling suggests that pups do not passively accept milk delivered to their mouths but actively consume it, and that rhythmic sucking is an important component of this ingestive behavior.

In these experiments we examine more closely the control of sucking and milk consumption. More specifically, we attempt to determine which aspects of maternal deprivation (nutritive, perioral, tactile, or olfactory deprivation) are involved in the control of rhythmic sucking, whether milk availability increases the frequency of rhythmic sucking, and whether rhythmic sucking might lead, in turn, to increased milk consumption.

\section{Experiment I}

Separation from the mother involves several different kinds of deprivation. Maternally deprived pups are deprived of nutrient, perioral stimulation derived from sucking, tactile stimulation derived from huddling, the olfactory properties of the mother, heat, and moisture. In this experiment we tested the contribution of gastrointestinal factors to the increase in sucking which occurs following maternal separation (e.g. Brake \& Hofer, 1980; Brake et al., 1979; Brake, et al., 1982). We reasoned that if gastrointestinal factors play a role in the elevation of sucking, then a $5 \%$ body-weight preload of milk administered before testing should attenuate this increase, just as $5 \%$ preloads depress milk consumption in suckling pups (Hall \& Rosenblatt, 1978; Lorenz et al., 1982). We also compared the sucking of pups which were allowed to consume freely available milk during the 30 -min test with the sucking of pups which were not allowed to consume milk while suckling, since preloads might differentially affect sucking in these 2 situations, as well as the amount of milk consumed by pups with access to it. Thus, half of the pups in each of the 3 groups had access to continuously available milk during the 30 -min test (via a posterior tongue cannula), and half did not.

\section{Method}

\section{Subjects}

The subjects were 24 male and 24 female 11-13-day-old rat pups. The pups were born of Marland Farm Wister dams in the animal care facility of Montefiore Hospital. Dams and litters were housed in $40 \times 20 \times 24-\mathrm{cm}$ plastic terraria in temperature- and humidity-controlled rooms. The light/dark regimen was $12: 12 \mathrm{hr}$, with light onset at 7:00 a.m. Litters were culled to 9 pups on Day 3 (day of birth was counted as zero). Food and water were continuously available.

\section{Design}

Six groups were run, each consisting of 4 male and 4 female pups drawn from at least 3 different litters. Four groups of pups were maternally deprived 20-24 hr prior 
to testing, and 2 groups were deprived $4 \mathrm{hr}$ prior to testing. Two of the groups deprived for $20-24 \mathrm{hr}$ and 1 of the groups deprived for $4 \mathrm{hr}$ received no milk during the suckling test ("dry" test). The 3 remaining groups ( 2 deprived for $20-24 \mathrm{hr}, 1$ deprived for $4 \mathrm{hr}$ ) received a slow infusion of milk during the suckling ("milk") test. One of the 20-hr groups in the "milk" test condition and 1 of the 20-hr groups in the "dry" test condition received a $5 \%$ body-weight preload of nutrient to the stomach by gavage $30 \mathrm{~min}$ prior to testing. Pups in all other groups were simply intubated $30 \mathrm{~min}$ prior to testing.

\section{Procedure}

Separation and surgery. Twenty to twenty-four hr, or $4 \mathrm{hr}$, prior to testing, pups were removed from their mothers and implanted with EMG recording electrodes as described by Brake et al. (1979). Briefly, pups were placed under light ether anesthesia and a $1.0-1.5-\mathrm{cm}$ incision was made along the midline of the underside of the pup's jaw, exposing left and right digastric muscles. Bipolar electrodes of fine Teflon-coated silver wire (Medwire, .25-mm diameter) were inserted into the left muscle. The leads were run under the skin of the neck and out a puncture wound behind the head and secured. Electrode placement required 5-10 min, entailed no damage to the muscle, and pups were recovered within $2 \mathrm{hr}$. We have found in repeated experiments that the length of time between surgery and testing ( $4 \mathrm{hr}$ or $24 \mathrm{hr}$ ) does not differentially affect the quality of the EMG measure.

Pups that were to receive milk (half-and-half) during testing were also fitted with a posterior tongue cannula of PE-10 tubing (Clay-Adams) according to the procedure described by Hall \& Rosenblatt (1977). The tongue cannula does not interfere with sucking and milk delivered to suckling pups through the posterior cannula arrives at the same point on the tongue as it does when delivered via the nipple, and is responded to by the pups as if it were coming from the nipple.

Following surgery, pups were individually placed in small plastic containers which were then enclosed in a warm $\left(33^{\circ} \mathrm{C}\right)$, moist $(50-70 \%$ relative humidity) incubator (Forma Scientific Diurnal Growth Chamber) for the duration of their deprivation periods.

Preloads. Thirty min prior to testing pups were weighed and rectal temperatures were recorded. Designated pups were then given a 5\% body-weight infusion of commercially available "half-and-half' (Queen's Farms) to the stomach. Infusions were given by gavage over a 1-2-min period. Pups not receiving preloads were simply intubated. All pups were then returned to their small plastic containers and enclosed in the incubator until testing.

Testing. Sucking was measured by recording jaw-muscle electromyographic activity (Brake et al., 1979). Electrode leads were connected to a Grass Model 7 polygraph and the pup placed with an anesthetized (urethane, $2 \mathrm{~g} / \mathrm{kg}$ ) nonlactating dam in a $30 \times 15$ $X 15-\mathrm{cm}$ plastic tub. Both rows of nipples were accessible. Urethane ordinarily blocks milk letdown, but dams were nevertheless checked for milk prior to and subsequent to each pup's test. If milk was detected in any nipple, another dam was substituted or the pups' data discarded.

"Milk" test pups received half-and-half through the tongue cannula as they suckled. The amount of fluid they received was contingent, to some extent, on the frequency and vigor of their sucking. This was accomplished by employing an open-ended reservoir system. The free end of the PE-10 tongue cannula was attached to a 30-gauge needle which was then attached to a $1-\mathrm{ml}$ syringe. The plunger was removed from the syringe, and the syringe was filled with half-and-half while vertically suspended $20 \mathrm{~cm}$ above the suckling pup. Pilot work with this system had shown that 11-13-day-old pups receive about $.01 \mathrm{ml} / \mathrm{min}$ of half-and-half through siphoning action alone but that they could 
greatly increase the rate of flow, up to $.02-.03 \mathrm{ml} / \mathrm{min}$, by sucking vigorously. Thus, milk was freely available during the 30 -min test, but was not delivered at a rate too rapid for the pup to swallow, and milk delivery was contingent largely upon the pup's behavior. This method of milk delivery is probably not unlike the situation the pup encounters a few seconds following discrete milk ejection when milk remains in the ducts of the teat (milk can be easily expressed from the nipple at this time). Still, the procedure was not designed to mimic the dam's intermittent milk-ejections (Lincoln, Hill, \& Wakerly, 1973). It was designed to have advantages as an experimental preparation. It allows precise measurement of fluid consumed, and it allows the pup constant access to freely available milk without forcing the pup to continuously swallow in order to clear the oral cavity. Thus, the use of the continuous-delivery system is a useful experimental device for determining the pup's capacity to regulate intake.

Pups were tested individually for $30 \mathrm{~min}$. Jaw-muscle EMG was recorded continuously. The pup's initial latency to attach to the nipple was also recorded, as was the amount of time the pup spent unattached to a nipple.

\section{Results and Discussion}

\section{EMG Scoring}

EMG records were independently scored by 2 trained raters. Raters were able to reliably identify 3 different types of muscle activity. These were the same types of muscle activity we have observed previously (Brake et al., 1979). There were "bursts," characterized as discrete episodes of high-frequency activity lasting at least $2 \mathrm{sec}$; "treadles," characterized as discrete episodes of slow-wave movement artifacts (pups moved their forelimbs during treadles) lasting at least $2 \mathrm{sec}$; and "rhythmic," characterized as discrete periods of regularly alternating increases and decreases in muscle activity lasting at least 5 $\mathrm{sec}$, with no more than $2 \mathrm{sec}$ separating each activity "peak." Interrater reliably in identifying each of these types of episodes ranged from 85 to $95 \%$.

We know from past (Brake et al., 1979) and ongoing research that bursts, treadles, and rhythmic patterns are indeed muscle-activity representations of actual intraoral sucking. The sucking underlying the rhythmic muscle pattern is characterized by a relatively long series of slow, deep, evenly distributed waves of negative intraoral pressure, each of these waves lasting about $2 \mathrm{sec}$. A slight opening and closing of the mouth is sometimes visible during rhythmic sucking. The sucking represented by both bursts and treadles is characterized as a brief grouping of irregularly spaced waves, each lasting less than $1 / 2 \mathrm{sec}$. In this study, and in previous ones, we found that the 2 major distinctions between bursts and treadles are that limb movements accompany treadles and not bursts, and that treadles are of longer average duration $(8-12 \mathrm{sec})$ than bursts $(3-5 \mathrm{sec})$. In contrast to "rhythmic" sucking, however, they are very similar and we refer to them together as "arrhythmic" sucking (Fig. 1).

\section{Group Differences}

Of the 4 groups of pups which received no preload (2 "dry" tests and 2 "milk" tests), those that were deprived for 20-24 hr engaged in significantly more sucking than those deprived for only $4 \mathrm{hr}$ [Fig. 2; ANOVA, $F(5,42)=8.79, p<.01$; post-hoc test, Scheffé $F(3,42)=3.99, p<.05]$. Thus, prior maternal deprivation seems to stimulate subsequent sucking. Of these same 4 groups of pups, those that were allowed access to milk while sucking engaged in significantly more sucking than those that received no milk while 


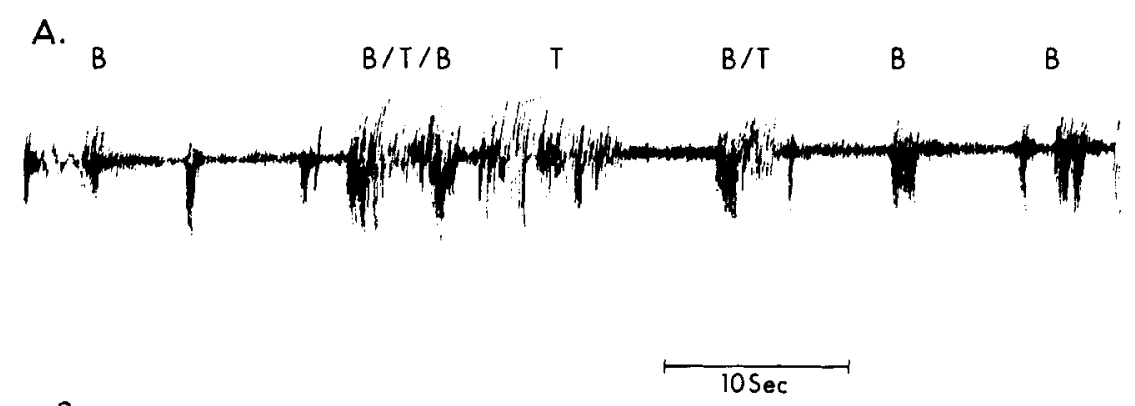

B.

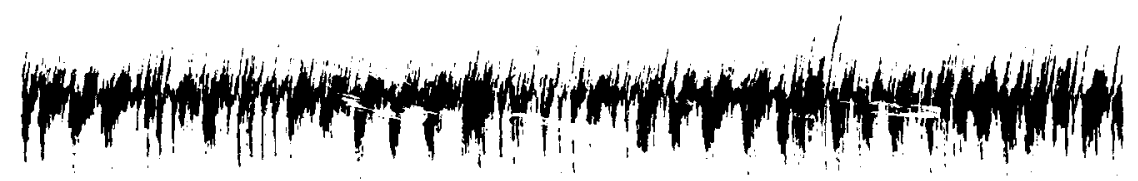

Fig. 1. Representative EMG recordings. Line $A$ is an example of arrhythmic sucking, Line $B$ is an example of rhythmic sucking. B and T in line A designate "burst" and "treadle".

sucking [Fig. 2; Scheffé $F(3,42)=8.77, p<.01$ ]. Thus, while maternal deprivation acts to increase the frequency of sucking during the subsequent suckling test, access to freely available milk during the test increases sucking to an even greater extent. Further, all changes in sucking frequency were due to changes in frequency of rhythmic sucking; there were no differences in frequency of arrhythmic sucking among any of the groups (Table 1).

Comparison of preloaded and nonpreloaded pups deprived for 20-24 hr revealed that while $5 \%$ preloads had no effect on the frequency of sucking for those pups which were not allowed to receive milk during the test, preloads did result in significantly less sucking in those pups allowed access to milk during the test [Fig. 2 ; Scheffé $F(1,42)=10.12, p$ $<.01$ ]. This suggests that the increase in "nonnutritive" rhythmic sucking elicited by maternal separation is not due to nutritive deprivation or gastrointestinal cues but that gastrointestinal cues contribute to the control of sucking during ingestion. Further, the preloads appear to block only the increase in rhythmic sucking which can be attributed to milk delivery. This effect might be mediated by the caloric value of the preload or to stomach distension cues (e.g. Lorenz et al., 1982). In either case, the behavioral effects of

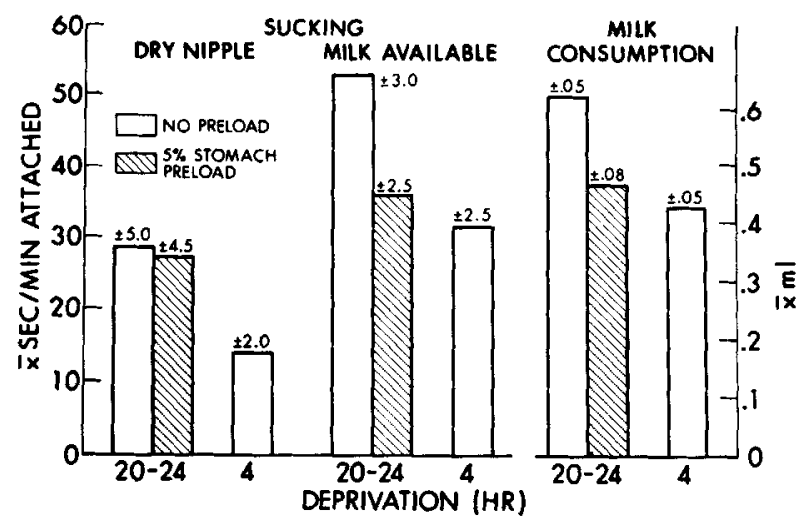

Fig. 2. Mean total sec of sucking/min attached to the nipple (thythmic and arrhythmic sucking combined), and mean amount of milk consumed. ( \pm Refers to standard error of the mean.) 
TABLE 1. Rhythmic Sucking, Arrhythmic Sucking, Initial Latency to Attach to th Nipple, and Time Spent Unattached to the Nipple for Groups in Experiment $I^{\text {a }}{ }^{\text {a }}$

\begin{tabular}{|c|c|c|c|c|}
\hline & $\begin{array}{l}\text { Rhy thmic } \\
\text { Sucking }\end{array}$ & $\begin{array}{l}\text { Arrhy thmic } \\
\text { Sucking }\end{array}$ & $\begin{array}{c}\text { Attachment } \\
\text { Latency }\end{array}$ & $\begin{array}{c}\text { Time of } \\
\text { Nipple }\end{array}$ \\
\hline & \multicolumn{2}{|c|}{$(\bar{x} \mathrm{sec} / \mathrm{min}$ attached $)$} & \multicolumn{2}{|c|}{$(\bar{x} \mathrm{sec})$} \\
\hline \multicolumn{5}{|l|}{ Dry Nipple } \\
\hline $20-24 \mathrm{hr}, 5 \%$ preload & 12.2 & 11.8 & 190.3 & 25.4 \\
\hline $20-24 \mathrm{hr}$, no preload & $\left.1 \Gamma^{-13.1}\right\rceil$ & 12.0 & 105.7 & 56.2 \\
\hline $4 \mathrm{hr}$, no preload & {$[4.3]^{2}$} & 14.0 & 65.2 & 33.6 \\
\hline \multicolumn{5}{|l|}{ Milk Available } \\
\hline $20-24 \mathrm{hr}, 5 \%$ preload & $19.47^{3}$ & 15.7 & 160.4 & 12.7 \\
\hline $20-24 \mathrm{hr}$, no preload & 31.4 & 16.4 & 120.3 & 10.3 \\
\hline $4 \mathrm{hr}$, no preload & $\mathrm{L}_{16.2} \mathrm{~J}^{\mathrm{J}}$ & 15.1 & 230.4 & 53.8 \\
\hline
\end{tabular}

${ }^{\mathrm{a}}$ Comparisons 1,2 , and 3 are statistically significant by Scheffé test.

the preloads were quite specific; they affected only rhythmic sucking and not the pup's frequency of limb movement (treadles), its initial latency to attach, or the amount of time it spent unattached to a nipple.

The amount of milk consumed during the suckling test reflected the frequency of the pups' sucking. Pups that were deprived for 20-24 hr and not given a preload consumed more milk during the test than pups in the other 2 "milk" test groups [Fig. $2 ; F(2,21)$ $=3.53, p<.05]$. These results fit nicely with data reported by Lorenz et al. (1982) showing that very young pups regulate intake even though they do not shift from 1 nipple to another, presumably by sucking. Rhythmic sucking is probably not the only means by which pups withdraw milk during milk delivery, but ongoing work in our laboratory suggests that pups control the frequency of rhythmic sucking even during oxy tocin-elicited milk-ejections.

None of the manipulations of this experiment seemed to affect the pups' initial latency to attach to the nipple or how long they stayed attached to the nipple. These data are in agreement with those of others (Cramer et al., 1980; Hall \& Rosenblatt, 1978; Lorenz et al., 1982) and suggest that the olfactory/tactile mechanisms which facilitate nipple attachment (Hofer, Fisher, \& Shair, 1981; Hofer, Shair, \& Singh, 1976; Teicher \& Blass, 1977) function independently of the mechanisms which affect sucking and/or ingestion.

\section{Experiment II}

In this experiment we examined nonnutritive factors responsible for the increase in rhythmic sucking which occurs following lengthy maternal deprivation. Since preloads did not reduce this increase in sucking in Experiment $I$, we reasoned that gastrointestinal cues are probably not important in this respect. However, suckling deprivation and olfactory deprivation are also components of maternal deprivation, and we reasoned that by supplying these cues (the sensation of sucking, the odors of the dam) during the deprivation period we might reduce the deprivation-related increase in sucking. As in Experiment I, sucking and nipple attachment were assessed during both "milk" and "dry" suckling tests. And, to be certain that gastrointestinal cues have no effect on the deprivation-related increase in sucking, we again administered preloads to half of the subjects. 


\section{Method}

\section{Subjects}

The subjects were 24 male and 24 female 11-13-day-old Wistar rat pups. Pups were culled and housed as described in Experiment $I$.

\section{Design}

Six groups were run, each consisting of an equal number of male and female pups drawn from at least 3 different litters. Pups of 2 groups were separated from an anesthetized dam during the 20-24-hr "deprivation" period by a wire-mesh partition. These pups could smell the dam, but not contact her. One of these 2 groups received a $5 \%$ body-weight preload 30 min prior to testing, and both groups were given "dry" tests (suckling in the absence of milk). Four other groups were placed with an anesthetized, nonlactating dam (in subgroups of 2) during the 20-24 hr "deprivation" period. These pups could smell, contact and suckle the dam, but they received no milk. Two of these groups received a 5\% preload prior to testing, and 2 did not. One preload and 1 no-load group received a "dry" suckling test, and 1 preload and 1 no-load group received a "milk" suckling test.

\section{Procedure}

Surgery. Twenty to twenty-four hr prior to testing all pups were implanted with EMG electrodes as described in Experiment I. "Milk" test pups were also equipped with a posterior tongue cannula at this time.

Anesthetized mothers. Mothers were anesthetized with urethane $(2 \mathrm{~g} / \mathrm{kg})$. To be sure pups received no milk from the anesthetized dam, we checked for milk in the nipples prior to and subsequent to the 20 -hr deprivation period. On 3 occasions we videotaped the entire 20-24-hr period to insure that pups were indeed contacting and suckling the anesthetized dam. The videotapes revealed that pups suckled an average of 13.1 out of $20 \mathrm{hr}$.

Loads. Thirty min prior to testing, designated pups were given a 5\% body-weight preload of half-and-half, as in Experiment $I$.

Testing. In general, testing occurred as described in Experiment 1 . The anesthetized dam employed during half of the suckling tests was one which had been placed adjacent to, or with, pups during the 20-24-hr deprivation period, rather than a recently anesthetized dam. This manipulation had no significant effect on sucking or milk intake measures.

\section{Results and Discussion}

Pups left with the nonlactating dam for 20-24 hr sucked less frequently during the "dry" suckling test than did pups which had been placed adjacent to the dam [Fig. 3; ANOVA, $F(5,42)=17.88, p<.01$; Scheffé $F(3,42)=3.08, p<.05$ ]. In fact, pups which had been placed with the nonlactating dam for 20-24 hr appeared to engage in no more frequent sucking than pups which had been maternally deprived for only 4 hr in Experiment I. On the other hand, pups which had been placed adjacent to the dam for 20-24 hr appeared to suck as frequently during the "dry" suckling tests as pups which had been maternally deprived for 20-24 hr in Experiment I. Notice also that, 


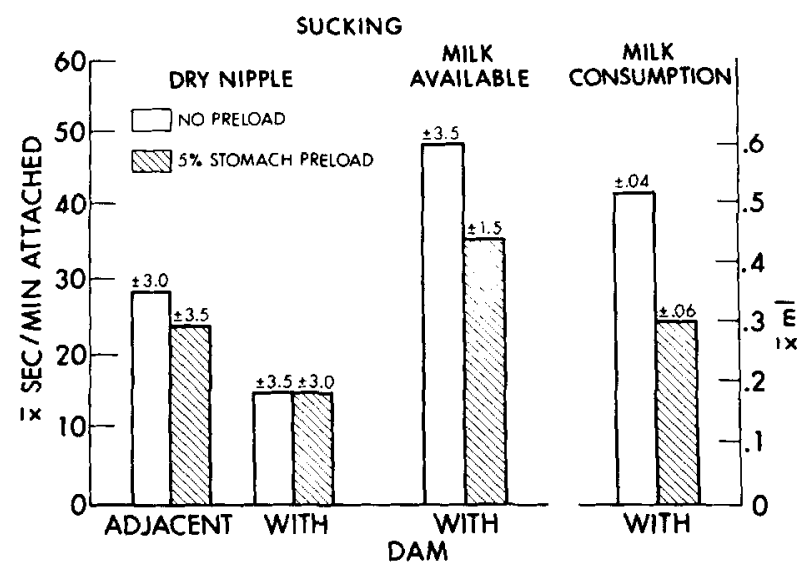

Fig. 3. Mean total sec of sucking/min attached to the nipple (rhy thmic and arrhythmic sucking combined), and mean amount of milk consumed. ( \pm Refers to standard error of the mean.)

as in Experiment I, preloads had no effect on sucking while pups were suckling in the absence of milk. These data suggest that the high frequency of rhythmic sucking which occurs following maternal deprivation is due to suckling deprivation, not nutritive deprivation. This interpretation would be consistent with the findings of Williams, Hall, and Rosenblatt (1980), who reported that older pups deprived of suckling, but not food, suckled as avidly as pups deprived of both suckling and food. We should note that nutritive deprivation might ordinarily increase the frequency of sucking, but that this effect was overshadowed here by what might be called "suckling satiation." Since we allowed pups to suckle an anesthetized, nonlactating dam for up to $24 \mathrm{hr}$, pups might have become sated with respect to suckling, or might even have learned that their sucking resulted in the delivery of no milk, and hence sucked less frequently.

Pups left with a nonlactating dam for 20-24 hr and allowed access to milk during the suckling test ("milk" test) engaged in more frequent sucking than pups which had been placed with the dam but allowed no milk during the test [Fig. 3; Scheffé $F(3,42)$ $=15.9, p<.01]$. Thus, as in Experiment $\mathrm{I}$, availability of milk during the suckling test seems to have stimulated sucking, even though these pups, too, were presumably "sucking satiated." Also as in Experiment I, preloads attenuated the frequency of sucking only in those pups receiving milk during the test [Scheffé $F(1,42)=6.91, p<.05]$. Preloads resulted in decreased consumption of milk as well [Scheffé $F(1,14)=9.30, p<.01$ ] . These findings again suggest that gastrointestinal cues are important in the control of sucking but only to the extent that gastrointestinal fill counteracts the stimulating affects of milk delivery.

As in Experiment I, differences in rhythmic sucking account for all differences in total combined sucking among the 6 groups [Table $2 ; F(5,42)=12.30, p<.01$ ] . Arrhythmic sucking was unaffected by any manipulation.

Unlike in Experiment I, pups differed in their initial latency to attach to the nipple and in the time they spent unattached to the nipple (Table 2). Pups which had been placed with the nonlactating dam for 20-24 hr took much longer to attach to the nipple than did pups which had been placed adjacent to the dam, again demonstrating the effect of suckling satiation. A Kruskal-Wallis ANOVA (pups fell into 2 groups, those that attached rapidly and those that did not) indicated that pups placed with the dam overnight took significantly longer to attach to the nipple than did pups placed adjacent to the dam ( $H=11.83, d f=5, p<.05 ; 2$-tailed). In addition, pups which had been placed with the nonlactating dam for $20-24 \mathrm{hr}$, and which received no milk during the suckling 
TABLE 2. Rhythmic Sucking, Arrhythmic Sucking, Initial Latency to Attach to the Nipple, and Time Off the Nipple for Groups in Experiment II. ${ }^{\mathrm{a}}$

\begin{tabular}{|c|c|c|c|c|}
\hline & $\begin{array}{c}\text { Rhythmic } \\
\text { Sucking }\end{array}$ & $\begin{array}{l}\text { Arrhy thmic } \\
\text { Sucking }\end{array}$ & $\begin{array}{l}\text { Attachment } \\
\text { Latency }\end{array}$ & $\begin{array}{c}\text { Time Off } \\
\text { Nipple }\end{array}$ \\
\hline & \multicolumn{2}{|c|}{$(\bar{x} \mathrm{sec} / \mathrm{min}$ attached $)$} & \multicolumn{2}{|c|}{$(x \sec )$} \\
\hline \multicolumn{5}{|l|}{ Dry Nipple } \\
\hline Adjacent, no preload & 8.8 & 11.1 & 233.4 & $551.3\rceil$ \\
\hline Adjacent, $5 \%$ stomach preload & L13.4 & 13.3 & -203.5 & $5[|110.9|$ \\
\hline With dam, no preload & ${ }^{1}\left[\begin{array}{ll}1 \\
\end{array}\right.$ & 9.8 & $4 \mid-503.5$ & || 217.5 \\
\hline With dam, $5 \%$ stomach preload & $\left.\mathrm{d}^{L}-5.3\right]$ & 9.3 & 602.4 & -201.4 \\
\hline \multicolumn{5}{|l|}{ Milk Available } \\
\hline With dam, no preload & {$[37.87$} & 10.3 & 403.5 & 9.7]] \\
\hline With dam, $5 \%$ stomach preload & dd $[25.5]$ & 9.8 & $L_{716.4}$ & $\left.13.2\right|^{2}$ \\
\hline
\end{tabular}

\footnotetext{
${ }^{a}$ Comparisons 1,2 , and 3 are statistically significant by Scheffé test; comparisons 4,5 , and 6 are statistically significant by Kruskal-Wallis ANOVA.
}

test, spent more time unattached to a nipple than pups which had been placed adjacent to the dam ( $H=7.96, f=3, p<.05 ; 2$-tailed). Pups which received milk during the test spent considerably less time unattached to a nipple than all other pups $(H=13.6, d f=5$, $p<.05 ; 2$-tailed), even though some pups were at first extremely reluctant to attach. These results support our earlier findings that the frequency of rhythmic sucking decreases, and the incidence of nipple detachments increases, as pups continue to suckle in the absence of milk (Brake \& Hofer, 1980; Brake et al., 1979). Interestingly, the videotape recordings of pups placed with the anesthetized dam for 20-24 hr further illustrate this point. These pups spent progressively more time unattached to the dam's nipples as the $20-24$-hr period neared completion.

\section{Experiment III}

In this experiment we examined the interaction between the "stimulating" effects of milk delivered to the mouth and the "attenuating" effects of milk delivered directly to the gastrointestinal tract. We infused preloads of milk directly into the mouths of 2 groups of pups 30 min prior to allowing them to suckle the anesthetized dam. Two other groups of pups received gastrointestinal preloads. One group from each of these preload conditions was allowed to receive milk during the suckling ("milk") test, and 1 group was not (“dry" test).

\section{Method}

\section{Subjects, Design, and Procedure}

The subjects were 16 male and 16 female 11-13-day-old Wistar rat pups. Pups were culled and housed as previously described. A total of 4 groups were run, each consisting of 4 male and 4 female pups drawn from at least 3 different litters. All pups were separated from the dam and operated on 20-24 hr prior to the suckling test. 
Two groups of pups received a $5 \%$ preload of milk delivered directly to the mouth via a posterior tongue cannula. Preloads were administered $21 / 2 \mathrm{hr}$ prior to the suckling test and required $2 \mathrm{hr}$ to complete because the milk was siphoned to the pups at a rate which allowed them to swallow it easily. Pups were not allowed to suckle during preloading. One of these 2 groups of pups received a "milk" suckling test following preloading, and 1 group of pups received a "dry" suckling test.

The 2 remaining groups of pups received a $5 \%$ preload of milk delivered directly to the gastrointestinal tract. These preloads required 2-3 min and were completed 30 min prior to the suckling test. One of those groups of pups then received a "milk" suckling test and 1 group received a "dry" suckling test. The "milk" and "dry" suckling tests were administered as described in the previous experiments.

\section{Results and Discussion}

Pups that had received intraoral preloads prior to the "dry" suckling test engaged in more suckling than pups in any of the other groups [Fig. $4 ; F(3,28)=2.98, p<$ .05]. None of the other groups differed from each other with respect to sucking frequency, or amount of milk consumed during the "milk" test. These data suggest an intricate interaction of cues from the gastrointestinal tract and oral cavity in control of sucking. Although gastrointestinal preloads had no effect on sucking frequency during the "dry" test (as in Experiments I and II), intraoral preloads seemed to stimulate sucking as much as milk delivered during the suckling test in Experiment I. Apparently, the stimulating effects of milk delivery are relatively long-lasting and do not necessarily depend on the pups receiving the milk while attached to the nipple (see Brake et al., 1982). However, with milk available during the test, not only did gastrointestinal preloads reduce sucking as in Experiments I and II, but intraoral preloads also acted to reduce the stimulating effects of milk delivery. Extrapolating from these experiments, we may suppose that sucking is stimulated as a pup begins to consume milk, but attenuates as its stomach begins to fill.

As in the previous experiments, differences among the groups in mean frequency of sucking can probably be attributed to differences in the frequency of rhythmic sucking (Table 3). Thus, pups which received intraoral preloads prior to the "dry" suckling test tended to engage in more rhythmic sucking than did pups in any of the other 3

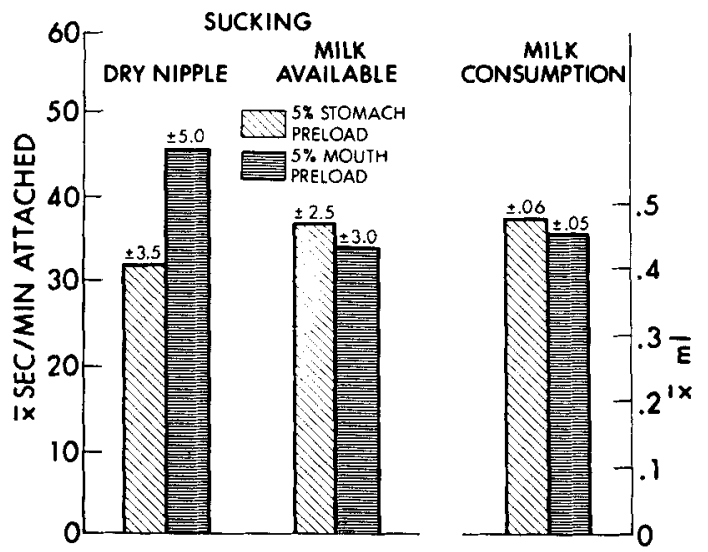

Fig. 4. Mean total sec of sucking/min attached to the nipple (rhythmic and arrhythmic sucking combined), and mean amount of milk consumed. ( \pm Refers to standard error of the mean.) 
TABLE 3. Rhythmic Sucking, Arrhythmic Sucking, Initial Latency to Attach to the Nipple, and Time Off the Nipple for Groups of Experiment III.

\begin{tabular}{lccccc}
\hline & $\begin{array}{c}\text { Rhythmic } \\
\text { Sucking }\end{array}$ & $\begin{array}{c}\text { Arrhythmic } \\
\text { Sucking }\end{array}$ & & $\begin{array}{c}\text { Attachment } \\
\text { Latency }\end{array}$ & $\begin{array}{c}\text { Time Off } \\
\text { Nipple }\end{array}$ \\
\cline { 5 - 6 } \cline { 5 - 6 } & & & & $(\bar{x}$ sec/min attached $)$ & \\
\hline Dry Nipple & 19.8 & 10.2 & & 78.3 & 5.4 \\
$\quad$ 5\% Stomach load & 28.0 & 14.9 & & 62.4 & 8.4 \\
5\% Mouth load & & & & \\
Milk Available & 19.4 & 15.7 & & 180.3 & 11.4 \\
5\% Stomach load & 19.9 & 16.8 & 172.4 & 9.9 \\
5\% Mouth load & & & & \\
\hline
\end{tabular}

groups, though statistical tests fell short of significance $(p<.08)$. Frequency of arrhythmic sucking differed only slightly among the 4 groups. No differences among groups were detected for the pups' initial latency to attach to the nipple, or for the time pups spent unattached to a nipple.

\section{General Discussion}

At least 4 broad conclusions can be drawn from this series of experiments. First, 11-13-day-old rat pups are capable of controlling the frequency of sucking while attached to a nipple, as well as the amount of milk consumed while sucking, if provided an unlimited amount. These are particularly interesting findings because environmental or privational manipulations have little effect at this age on the pups' willingness to attach and remain at tached to the nipple. For example, at 15 days of age and younger, pups seem to be attracted to the nipple whether sated or hungry, or whether maternally deprived or not (Cramer et al., 1980), suggesting that nipple-shifting and nipple detachment play little part in the control of milk intake until pups are older. Our results, on the other hand, indicate that pups as young as 11 days of age are capable of controlling intake by differentially controlling sucking. Our results are consistent with those of Hall and Rosenblatt (1978), who demonstrated that preloaded 10-day-old pups consume less milk than deprived pups, and with those of Lorenz et al. (1982), who showed that 5- and 10-day-old pups somehow achieve intake control without altering the amount of time they spend attached to a nipple.

Second, the control of both sucking and milk intake are complex matters mediated by the interaction of both intraoral and gastrointestinal stimuli. The frequency of the pup's sucking in the absence of milk availability ("nonnutritive" sucking) seems to be determined mostly by how long the pup has been deprived of the oral/tactile stimulation derived from suckling the nipple. Lengthy suckling deprivation increases subsequent sucking, but neither nutritive deprivation nor gastrointestinal fill appears to affect the frequency of the pup's "nonnutritive" sucking.

The frequency of the pup's sucking in the presence of milk availability is ordinarily greater than it is when no milk is available. However, the frequency of the pup's sucking and the amount of milk the pup is willing to consume seem also to be determined by other factors as well. The 1st of these is, again, how long the pup has been suckling. deprived. Availability of milk increases sucking frequency regardless of whether pups are 
suckling-deprived, but since the effects of milk availability and suckling deprivation appear to be additive, sucking-deprived pups engage in more sucking, and consume more milk, than do nondeprived pups. The 2 nd factor that influences sucking and milk intake is whether the gastrointentinal tract is full or empty. Gastrointestinal fill seems to block the otherwise stimulating effects of milk delivery. Thus, pups with a meal-sized volume of nutrient (or bulk) in their gastrointestinal tracts do not suck as avidly, or consume as much milk, as nutritively deprived pups. Further, gastrointestinal fill appears to block only that amount of sucking that can be attributed to milk delivery, as if the "incentive" value of milk delivered to the mouth were diminished. We cannot say with certainty whether these relationships hold strictly true in the natural suckling situation, which is characterized by the presence of suckling littermates, an awake dam, and different patterns of milk delivery. However, when the opportunity to attach, suck, and ingest milk is left solely to the individual pup, these are the relationships we find. Put in the most conservative language, we have demonstrated in these experiments what the pup is capable of doing.

Third, it appears that rhythmic sucking may be an important component of the pup's ingestive response repertoire. Interestingly, the response characteristics that distinguish between rhythmic and arrhythmic sucking (e.g. Brake et al., 1979) are very similar to those that distinguish between "nutritive" and "nonnutritive" sucking in human infants (Wolff, 1968). "Nonnutritive" sucking in human infants is characterized by a grouping of shallow, erratic, relatively rapid sucks, much like arrhythmic sucking in rats. "Nutritive" sucking, on the other hand, is characterized by deep, evenly spaced sucks in a long series of sucks, much like rhythmic sucking in rats. In humans, "nutritive" sucking appears with the onset of milk availability and is the infant's primary ingestive response. In our data, rhythmic sucking occurs both in the presence and absence of milk, but its primary function may nevertheless be as a consummatory response. While we cannot, on the basis of the present data alone, accurately discuss what might occur during an actual milk-ejection from the dam, we have found in other work (Shair et al., 1982) and in ongoing research that rhythmic sucking reliably increases during and immediately following milk ejection. In light of this, it seems quite likely that control of milk consumption is achieved mostly through manipulation of rhy thmic sucking.

Finally, nipple attachment measures (initial latency to attach to the nipple, time spent unattached to the nipple) seem little affected by privational manipulations. Pups are likely to attach to a nipple and remain there regardless of whether they are maternally or nutritively deprived. The 1 exception to this finding is that extensive (20-24-hr) suckling in the absence of milk increases the pup's subsequent attachment latency as well as the time it spends unattached to the nipple. This is similar to findings we have noted previously (Brake \& Hofer, 1980; Brake et al., 1979). It is also true that milk availability reduces the amount of time pups spend unattached to a nipple, but this is true of deprived and nondeprived pups alike, and is also an effect we have noted elsewhere (Brake et al., 1982). In general, the factors in our experiments that influence sucking and ingestion have little effect on nipple attachment. This suggests that "sucking" should be viewed as the interaction of 2 overlapping behavioral sequences. One has to do with the pup's approach to the nipple and how long it remains attached to the nipple, while the other has to do with what the pups does once attached to the nipple. Of course, neither are simple, unitary sequences. For example, the preweanling pup locates and attaches to the nipple on the basis of a variety of olfactory and tactile cues (Blass, Hall, \& Teicher, 1979; Hofer et al., 1976; Hofer et al., 1980). Similarly, the pup may increase or decrease its sucking according to whether its stomach is full, whether it has recently suckled a nipple, or whether it received milk when it suckled. 
The determinants of attachment behavior and sucking behavior overlap, particularly as the pup approaches weaning (Blass et al., 1979; Williams et al., 1980). It is, nevertheless, useful to consider the behaviors which occur while the pup is attached to the nipple as largely independent of the sequences which lead to nipple attachment.

\section{Notes}

This research was supported by NIMH Project Grant MH32429, awarded to Stephen C. Brake. The authors wish to thank Y. Rodriguez Ramos for technical assistance, and Herbert Weiner, Sigurd Ackerman, and Christina Williams for helpful comments.

\section{References}

Blass, E. M., Hall, W. G., and Teicher, M. (1979). The ontogeny of suckling and ingestive behaviors. In J. M. Sprague and A. N. Epstein (eds.), Progress in Psychobiology and Physiological Psychology. Volume 8. New York: Academic Press.

Brake, S. C., and Hofer, M. A. (1980). Maternal deprivation and prolonged suckling in the absence of milk alter the frequency and intensity of sucking responses in neonatal rat pups. Physiol. Behav., $24: 185-189$.

Brake, S. C., Sullivan, R., Sager, D. J., and Hofer, M. A. (1982). Short- and long-term effects of various milk delivery contingencies on sucking and nipple attachment in rat pups. Dev. Psychobiol., 15: 543-556 (the following paper).

Brake, S. C., Wolfson, V., and Hofer, M. A. (1979). Electrophysiological patterns associated with nonnutritive sucking in 11-13-day-old rat pups. J. Comp. Physiol. Psychol., 93:760-770.

Cramer, C. P., Blass, E. M., and Hall, W. G. (1980). The ontogeny of nipple-shifting behavior in albino rats: Mechanisms of control and possible significance. Dev. Psychobiol., 13:165-180.

Dollinger, M. J., Holloway, W. R., and Denenberg, V. (1978). Nipple attachment in rats during the first 24 hours of life. J. Comp. Physiol. Psychol., 92:619-626.

Hall, W. G., and Rosenblatt, J. S. (1977). Suckling behavior and intake control in the developing rat pup. J. Comp. Physiol. Psychol., 91:1232-1247.

Hall, W. G., and Rosenblatt, J. S. (1978). Development of nutritional control of food intake in suckling rat pups. Behav. Biol., 24:413-427.

Hofer, M. A., Fisher, A., and Shair, H. (1981). Fffects of infraorbital nerve section on survival, growth and suckling behaviors of developing rats. J. Comp. Physiol. Psychol., 95:123-133.

Hofer, M. A., Shair, H., and Singh, P. (1976). Evidence that maternal ventral skin substances promote suckling in infant rats. Physiol. Behav., 17:131-136.

Houpt, K. A., and Epstein, A. N. (1973). Ontogeny of controls of food intake in rat: GI fill and glucoprivation. Am. J. Physiol., 225:58-66.

Lincoln, D. W., Hill, A., and Wakerley, J. B. (1973). The milk-ejection reflex of the rat: An intermittent function not abolished by surgical levels of anesthesia. J. Endocrin., 57:459-476.

Lorenz, D., Ellis, S., and Epstein, A. (1982). Differential effects of upper gastrointestinal fill on milk ingestion and nipple attachment in the suckling rat. Dev. Psychobiol., 15:309-330.

Shair, H., Brake, S. C., and Hofer, M. A. (1982). Suckling in the rat: Evidence for patterned behavior during sleep. Unpublished manuscript.

Teicher, M. H., and Blass, E. M. (1977). First suckling response of the newborn albino rat: The roles of olfaction and amniotic fluid. Science, 198:635-636.

Williams, C. L., Hall, W. G., and Rosenblatt, J. (1980). Changing oral cues in suckling of weanling-age rats. J. Comp. Physiol. Psychol., 94:472-483.

Wolff, P. H. (1968). Suckling patterns of infant mammals. Brain Behav. Evol., 1:354-367. 